\title{
Evaluation de l'intensité territoriale de deux systèmes de cultures associées modérément fertilisées au Sud-Bénin
}

\author{
V. Naéssé ADJAHOSSOU ${ }^{1 *}$, B. Sêdami ADJAHOSSOU², \\ Flavien DOVONOU ${ }^{3}$, D. Firmin ADJAHOSSOU ${ }^{4}$ et Michel BOKO ${ }^{1}$ \\ ${ }^{I}$ Faculté des Lettres Arts et Sciences Humaines, Université d'Abomey-Calavi (FLASH/UAC), \\ BP 55 Abomey-Calavi, Bénin. \\ ${ }^{2}$ Ecole Polytechnique d'Abomey-Calavi (EPAC/UAC), 01BP 2417 Cotonou, Bénin. \\ ${ }^{3}$ Centre Béninois de la Recherche Scientifique et Technique, 03 BP : 1665. Cotonou, Bénin. \\ ${ }^{4}$ Faculté des Sciences Agronomiques, Université d'Abomey-Calavi (FSA/UAC), \\ 01 BP 526 Cotonou, Bénin. \\ *Auteur correspondant ; E-mail : vidnae@yahoo.fr
}

\section{RESUME}

L'Afrique de l'Ouest demeure la région où l'accroissement de la production alimentaire est plus faible que la progression démographique avec une économie trop faible pour soutenir une agriculture moderne, consommatrice d'intrants et d'énergie. Ainsi, l'une des alternatives pourrait être une amélioration des systèmes de cultures multiples, encore en usage dans la région. Pour ce faire, deux expérimentations basées sur un apport d'engrais NPK (10-20-20) et $10 \mathrm{t}$ de matière organique/ha, ont été conduites à Kpotomey au Bénin. L'une a associé l'arachide et trois variétés de maïs et l'autre a combiné le maïs, le manioc et le pois d'angole. L'objectif a été d'évaluer la productivité des différents systèmes de cultures étudiés par rapport à la superficie nécessaire pour satisfaire les besoins alimentaires. Les résultats montrent que l'intensité territoriale a varié de $2831,4 \mathrm{~m}^{2}$ à 495,6 $\mathrm{m}^{2}$ pour les associations impliquant l'arachide et le maïs et de $25000 \mathrm{~m}^{2}$ à $266,6 \mathrm{~m}^{2}$ pour celles basées sur le maïs, le manioc et le pois d'angole. Il est alors nécessaire de s'appuyer sur la minimisation de l'intensité territoriale afin de concilier au mieux la satisfaction des besoins alimentaires des populations et la préservation des terres arables qui constituent des ressources naturelles non extensibles.

(C) 2013 International Formulae Group. All rights reserved.

Mots clés : intensité territoriale, cultures associées, besoins alimentaires.

\section{INTRODUCTION}

Pour accroître la productivité de la terre, l'accent est souvent mis sur deux facteurs de production : le travail et le capital (Bonny, 2010). Ainsi, dans un système de cueillette, l'essentiel de l'investissement se mesure en temps. Il paraît alors logique que les rendements soient évalués par rapport au temps consacré pour récolter une quantité donnée de produits nécessaires pour la satisfaction des besoins alimentaires journaliers. Comme le souligne Sahlins (1976), il faut quelques heures à un individu pour récolter les céréales sauvages nécessaires pour nourrir quotidiennement une famille. L'évaluation des rendements des récoltes dans le contexte d'une agriculture traditionnelle dépourvue d'instruments de pesée, ne pouvait se faire que par rapport à la quantité de produits récoltés, et à la quantité de semences 
utilisées (Mazoyer et Roudart, 2002). La modernisation de l'agriculture s'est traduite par un important usage de pesticides, d'engrais (Le Roux et al., 2008; Papy et Goldringer, 2011) et nécessitant des infrastructures d'enseignement et de recherches (Revel et Riboud, 1981; Griffon, 2002). Elle vise alors les rendements les plus élevés (Griffon, 1999) afin de rentabiliser ces investissements et tout en affirmant avoir toujours pour objectif de mieux nourrir l'homme. L'agriculture moderne, fortement impliquée dans une économie mondialisée devient pour les pays non développés, un facteur de sous-alimentation et une menace pour la préservation de l'environnement. La satisfaction des besoins alimentaires constitue la principale motivation qui conduit à la coupe à blanc des forêts en Afrique (Bellassen et al., 2008) et des savanes arborescentes.

Pour cette étude, l'intensité territoriale basée sur la superficie de terre nécessaire pour produire une ration alimentaire équilibrée en macronutriments ou en apport protéinoénergétique pour un adulte pendant un an, a été évaluée à partir des rendements agronomiques. Elle vise d'abord à recentrer l'agriculture sur la satisfaction des besoins alimentaires des producteurs puis des autres couches de la société pour disposer de moyens financiers et satisfaire à des besoins non alimentaires.

Dans l'état actuel de l'économie des pays d'Afrique au Sud du Sahara, l'intensification des systèmes agraires traditionnels caractérisés par divers types d'association de cultures pourrait améliorer l'efficacité territoriale de l'agriculture dans la région.

\section{MATERIEL ET METHODES}

\section{Matériel végétal}

\section{Première expérimentation}

Une variété locale d'arachide (Arachis hypogea) du groupe "spanish" de 90 jours, a été semée avec une densité de 11,1 plants $/ \mathrm{m}^{2}$. Elle a été associée avec trois variétés de maïs : la variété de maïs TZEEW (Tropical Zea
Extra Early White) à port érigé et ayant un cycle de 80 jours; la variété DMR-ESRW (Downly Middew Resistent Early Streak White) à port semi-retombant ayant un cycle de 120 jours; la variété Obatanpa, riche en protéines (QPM) dont le cycle est de 105 jours.

\section{Deuxième expérimentation}

Elle a porté sur le composite Obatanpa riche en protéines, l'une des trois variétés de maïs utilisées et décrites dans l'expérimentation précédente. Le pois d'angole est une variété locale de consommation courante acquise au marché. Le manioc associé à ces espèces est la variété BEN 86052.

\section{Dispositifs expérimentaux \\ Première expérimentation}

Le dispositif expérimental est un bloc aléatoire complet (BAC) avec quatre répétitions. Les combinaisons de l'arachide avec trois variétés de maïs de ports différents, constituent les traitements. Chaque bloc comporte sept parcelles: une parcelle d'arachide en culture mono spécifique, trois parcelles portant l'une des trois variétés de maïs TZEEW, DMR-ESRW, Obatanpa, en culture mono spécifique et enfin trois autres parcelles portant l'association de l'arachide avec chacune des trois variétés de maïs.

\section{Deuxième expérimentation}

Le dispositif expérimental est un carré latin constitué de quatre blocs aléatoires avec une randomisation totale. Chaque bloc comporte quatre parcelles à savoir : une parcelle de maïs en culture mono spécifique, une parcelle de manioc en culture mono spécifique, une parcelle de pois d'angole en culture mono spécifique et une parcelle portant l'association de maïs, du manioc et du pois d'angole. Les blocs sont orientés estouest dans le sens de la pente.

\section{Conditions de culture}

Les essais ont été réalisés sur un sol ferralitique dont la fertilité a été améliorée par 
une application de $100 \mathrm{~kg} / \mathrm{ha}$ d'engrais chimique ternaire NPK (10-20-20).

\section{Première expérimentation}

Un apport complémentaire de 10 t/ha de matières organiques sous forme de paillage a été fait. L'alimentation en eau des cultures a été assurée par l'eau pluviale et par un système d'irrigation d'appoint pour couvrir la demande maximale équivalente à l'ETP, estimée à $5 \mathrm{~mm} / \mathrm{j}$.

\section{Deuxième expérimentation}

Huit tonnes de folioles et brindilles de Leucaena diversifolia ont été apportées comme engrais organique. L'alimentation en eau des cultures a été assurée par l'eau pluviale.

Pour empêcher le déterrement des semences par les oiseaux et les petits rongeurs, et les attaques des insectes, les grains de maïs, l'arachide, et le pois d'angole ont été trempés dans un mélange contenant de la cendre et des feuilles de Azadirachta indica triturées dans de l'eau.

Le semis des graines et la plantation du manioc ont été faits dans le sens de la pente (Est- Ouest).

\section{Collecte et traitement des données Pesées}

Les pesées pour l'estimation de la bioproduction ont été faites d'une part à l'aide d'une balance "Five goals" de $20 \mathrm{~kg}$ de portée maximale et de $50 \mathrm{~g}$ de sensibilité et d'autre part, avec une balance électronique de cuisine de marque Tefal, de portée maximale de $3 \mathrm{~kg}$ et de $1 \mathrm{~g}$ de sensibilité.

\section{Traitement des données}

\section{Détermination des Surfaces Equivalentes Relatives (SER)}

D'après IRRI (1974; 1975), la SER consiste à estimer la superficie de terre nécessaire pour obtenir en culture pure, la même production que sur une superficie de cultures associées prise comme référence. Elle évalue pour la même production, le gain de superficie de terre que le système de cultures associées permet éventuellement d'économiser par rapport aux systèmes de culture mono spécifique de chacune des espèces associées.

Pour un système de cultures associant par exemple les espèces a, b, c, la SER est calculée comme suit :

$\mathrm{SER}=\mathrm{P}_{\mathrm{a}} / \mathrm{P}_{\mathrm{a}}{ }_{\mathrm{a}}+\mathrm{P}_{\mathrm{b}} / \mathrm{P}^{\prime}{ }_{\mathrm{b}}+\mathrm{P}_{\mathrm{c}} / \mathrm{P}^{\prime}{ }_{\mathrm{c}}$

avec: $\mathrm{P}_{\mathrm{a}}$ : rendement de la plante $\mathrm{a}$ en association; $\mathrm{P}_{\mathrm{a}}$ : rendement de la plante a en culture pure ;

$\mathrm{P}_{\mathrm{b}}$ : rendement de la plante $\mathrm{b}$ en association;

$\mathrm{P}_{\mathrm{b}}$ : rendement de la plante $\mathrm{b}$ en culture pure ;

$\mathrm{P}_{\mathrm{c}}$ : rendement de la plante $\mathrm{c}$ en association;

$\mathrm{P}_{\mathrm{c}}$ : rendement de la plante $\mathrm{c}$ en culture pure.

Evaluation nutritionnelle

Elle a consisté, sur la base des rendements agronomiques, en l'estimation du nombre de rations alimentaires équilibrées en macronutriments que chaque système de culture fournit. Ainsi, il a été déterminé, à l'aide des coefficients mentionnés dans les Tableaux 1 et 2 les quantités de glucides, de protéines et de lipides contenus dans chaque culture. Ces calculs s'appuient sur les travaux de Purseglove (1979 a et b). Les nombres de rations alimentaires journalières ont été ensuite déterminés. En se basant sur les travaux de Cresta et al., (1994) réalisés dans le milieu d'étude et de ceux de Sagbohan (1996), on considère que les besoins moyens journaliers par individu adulte sont de $250 \mathrm{~g}$ de glucides, $56,7 \mathrm{~g}$ de protéines et $86,4 \mathrm{~g}$ de lipides. Ainsi, le nombre de rations alimentaires de chaque système de cultures est déterminé par la quantité de macronutriments (glucides, protéines ou lipides) et les besoins moyens journaliers correspondants.

Soient $\mathrm{Q}_{\mathrm{g}}, \mathrm{Q}_{\mathrm{p}}$ et $\mathrm{Q}_{\mathrm{l}}$, les quantités respectives de glucides, de protéines et de lipides d'un système de cultures et $\mathrm{B}_{\mathrm{g}}, \mathrm{B}_{\mathrm{p}}$ et $\mathrm{B}_{1}$, les besoins moyens journaliers correspondants. Le nombre de rations alimentaires $N_{R}$ du système, en glucide (par exemple) est : $\mathrm{N}_{\mathrm{Rg}}=\mathrm{Q}_{\mathrm{g}} / \mathrm{B}_{\mathrm{g}}$.

Le nombre de rations alimentaires équilibrées du système de culture correspond au plus petit nombre de rations fournies par les glucides, protéines ou lipides produits. 
Tableau 1: Coefficient de détermination des quantités de glucides, de protéines et de lipides contenues dans un kilogramme de chaque culture concernée.

\begin{tabular}{lccc}
\hline Cultures & Coefficient glucide & Coefficient Protéine & Coefficient lipide \\
\hline Maïs & 0,65 & 0,13 & 0,04 \\
Manioc & 0,89 & 0,025 & 0,01 \\
Feuilles manioc* & 0,34 & 0,28 & 0,06 \\
Pois d'angole & 0,57 & 0,2 & 0,015 \\
Arachide & 0,2082 & 0,2522 & 0,47 \\
\hline * La partie consommable est estimée à 20\% de la production totale de feuilles. &
\end{tabular}

* La partie consommable est estimée à $20 \%$ de la production totale de feuilles.

Tableau 2 : Détermination des rations alimentaires.

\begin{tabular}{lcc}
\hline Coefficient glucide & Coefficient Protéines & Coefficient lipides \\
\hline 0,25 & 0,0567 & 0,0864 \\
\hline
\end{tabular}

\section{Rendements en rations protéino-énergétiques et intensité territoriale}

Pour une personne adulte de la zone de l'expérimentation, Cresta et al. (1994) ont estimé à $2163 \mathrm{kcal}$ les besoins énergétiques journaliers et à $56,7 \mathrm{~g} /$ jour les besoins moyens en protéines. Sur ces bases, le nombre de rations protéino-énergétiques des systèmes de cultures a été calculé d'une part, à partir des rations équilibrées en macronutriments et d'autre part, à partir des productions alimentaires totales, avec une estimation des intensités territoriales correspondantes.

\section{Analyse statistique}

L'analyse de variance a été faite selon le dispositif de blocs aléatoires complets pour l'expérimentation associant l'arachide et trois variétés de maïs. La variable explicative est constituée par le type de système de culture défini par la combinaison de l'arachide avec des variétés de maïs de divers ports, toutes semées à la densité de 4,2 plants $/ \mathrm{m}^{2}$.

Pour l'association du maïs, manioc et pois d'angole, l'analyse de variance a été faite selon le modèle de carré latin. Les variables explicatives sont les rendements par hectare du maïs, du manioc, du pois d'angole en association, les rendements du maïs, du manioc, du pois d'angole en culture mono spécifique et le rendement global du système de culture en étude. La variable expliquée est la productivité.

L'analyse de variance, les erreurs standards des moyennes, la comparaison par paire par le test de Turkey ont été effectuées avec le logiciel Statistix 8. Le seuil de significativité est $\alpha=0,01$.

\section{RESULTATS}

\section{Rendements agronomiques et intensité territoriale}

Le Tableau 3 indique les rendements en grains (es) des divers systèmes de cultures associant l'arachide, au maïs DMR-ESRW, au maïs TZEEW et au maïs Obatanpa en produits alimentaires.

L'analyse de variances des données montre que les différences sont hautement significatives entre les rendements des divers systèmes de cultures avec $\alpha=0,01$ ( $\mathrm{p}=$ $0,001)$.

La comparaison par paire par le test de Turkey (HSD) avec $\alpha=0,01$, fait ressortir trois groupes distincts et groupes intermédiaires. 
L'analyse de variance met en évidence des différences hautement significatives entre les rendements en grains de certains systèmes de cultures.

De la comparaison par paire par le test de Turkey (HSD), pour $\alpha=0,01$, il ressort que pour DMR-ESRW, les rendements en grains des parcelles dans lesquelles, le maïs est associé à l'arachide, sont très significativement différents de ceux des parcelles dans lesquelles le maïs a été semé en culture mono spécifique. La baisse de rendement est de $24,1 \%$.

En ce qui concerne la variété TZEEW, les différences entre les rendements ne sont pas significatives entre les parcelles dans lesquelles le maïs est en association avec l'arachide et les parcelles de maïs en culture mono spécifique.

L'ampleur de la différence entre les rendements respectivement de $671,8 \mathrm{~kg} / \mathrm{ha}$ pour l'arachide-Obatanpa et de $195,2 \mathrm{~kg} / \mathrm{ha}$ pour l'arachide-TZEEW, s'expliquerait par le fait que le potentiel de productivité de Obatanpa est de 4,5t/ha (Nourrir l'Avenir, 2002) et celui de TZEEW est de 3,5 t/ha (Fajemisin, 1991).

Le Tableau 4 récapitule les rendements en matière sèche du système de cultures associant le maïs, le manioc et le pois d'angole en culture mono-spécifique.

Le rendement moyen du maïs (variété Obatanpa) en association avec le manioc et le pois d'angole est de $2990,4 \mathrm{~kg} / \mathrm{ha}$. En culture mono spécifique, ce rendement a été de $3413,2 \mathrm{~kg} / \mathrm{ha}$. La comparaison par paire par le test de Turkey (HSD) avec $\alpha=0,05$ ( $\mathrm{p}=$ $0,001)$ montre que les deux valeurs ne sont pas significativement différentes.

Pour le manioc, la production de matière sèche de racines tubéreuses est de $5175 \mathrm{~kg} / \mathrm{ha}$ contre $6456 \mathrm{~kg} / \mathrm{ha}$ en culture mono spécifique, soit un gain de $24,75 \%$.

Les deux expérimentations associant d'une part l'arachide et trois variétés de maïs de ports différents et d'autre part le maïs, le manioc et le pois d'angole, montrent que les systèmes de cultures associées sont plus productifs que les systèmes mono spécifiques correspondants (Tableau 3 et 4).

Le Tableau 5 présente les surfaces équivalentes relatives correspondantes pour les deux expérimentations.

Ainsi, l'association de la variété TZEEW avec l'arachide, a généré la meilleure SER de 1,582 contre 1,366 et 1,214 pour respectivement, les associations Obatanpaarachide et DMR-ESRW-arachide. Ce qui exprime un avantage de rendement de 21,4 à $58,2 \%$ pour les cultures associées par rapport aux cultures mono spécifiques. En d'autres termes, les cultures mono spécifiques auraient exigé une superficie de terre supplémentaire de 21,4 ; de 36,6 et de $58,2 \%$ pour atteindre respectivement les performances des systèmes de cultures DMR-ESRW-arachide, Obatanpaarachide et TZEEW-arachide. Pour l'association du maïs-manioc-pois d'angole, la SER est de 2,5. Ce qui confirme bien que l'efficacité biologique d'un système de cultures, dans certaines limites, s'accroît proportionnellement au nombre de cultures (Steiner, 1985).

Il apparaît que l'association des cultures est donc susceptible de réduire, dans les cas étudiés, de $20 \%$ à $150 \%$, l'intensité territoriale. Cependant, il est nécessaire d'examiner l'impact de l'amélioration des rendements sur la satisfaction des besoins alimentaires, en termes de superficie nécessaire pour assurer pendant un an, une ration alimentaire équilibrée en macronutriments dans la zone de l'étude par jour étant de $288 \mathrm{~g}$ de glucide, 56,7 $\mathrm{g}$ de protéines et $86,4 \mathrm{~g}$ de lipides.

\section{Rendements en rations alimentaires équilibrées et intensité territoriale}

Le Tableau 6 présente la quantité de macronutriments de deux systèmes de cultures combinant d'une part, l'arachide aux trois variétés de maïs de différents ports (première expérimentation) et d'autre part, l'association 
comprenant le maïs, le manioc et le pois d'angole (deuxième expérimentation).

Avec la première expérimentation, la variété DMR-ESRW a fourni la quantité de glucide la plus importante qui est de 3353,6 $\mathrm{kg}$ par hectare. Par contre, le système de culture mono spécifique le moins productif est l'arachide avec $371,7 \mathrm{~kg} / \mathrm{ha}$. En ce qui concerne les protéines, l'association Obatanpa-Arachide en a produit la plus grande quantité qui est de 688,9 kg/ha. La quantité la plus importante de lipides est générée par l'arachide avec 794,1 kg/ha.

Pour la deuxième expérimentation, le rendement (7 094,6 $\mathrm{kg} / \mathrm{ha}$ ) en glucides du système de cultures associant les trois espèces est supérieur à ceux des cultures mono spécifiques du manioc, du maïs et du pois d'angole, respectivement de $19 \% ; 219 \%$ et $1349 \%$.

En ce qui concerne les protéines, ce système produit respectivement $255 ; 326$ et $574 \%$ de plus que les cultures mono spécifiques de maïs, de manioc et de pois d'angole.

Le Tableau 7 présente le nombre de rations moyens en glucides, protéines et lipides des deux différents systèmes de cultures et met en évidence l'influence de la carence de lipides sur le nombre de rations alimentaires équilibrées en macronutriments.

$\mathrm{Au}$ niveau de la première expérimentation, les nombres de rations en glucides et en protéines pour les systèmes mono spécifiques des trois types de maïs sont trois à cinq fois plus élevés que ceux des rations équilibrées. Il est à remarquer que la variété Obatanpa a fourni une ration constante pour ces deux macronutriments.

En raison d'une faible production en glucides, le nombre de rations le plus bas (1 290) concerne l'arachide en culture mono spécifique. Pour les trois cultures mono spécifiques à base des variétés de maïs, ce nombre varie de 1514 à 2429.

Par contre, l'association des deux cultures favorisant une meilleure interception de la lumière, améliore quantitativement la production. L'introduction de l'arachide dans le système de cultures de maïs améliore qualitativement la production en augmentant celles de lipides et de protéines sur une même surface (Adjahossou et al., 2009). Le nombre de rations alimentaires «équilibrées » que l'on peut produire par hectare, passe alors à un niveau supérieur allant de 6022 à 7369 .

Quant au second système regroupant le maïs, le manioc et le pois d'angole, le nombre total de rations alimentaires en glucides (24 634) du système associant ces trois cultures est 10,3 fois supérieur au nombre de rations équilibrées (2 400) retenu, imposé par la teneur en lipides comme facteur limitant. Pour les protéines, le nombre de rations alimentaires correspondant est 5,7 fois supérieur à cette valeur.

La différence entre le nombre de rations de glucides et celui des protéines est égale à 10 926. Cette différence est de 22234 en ce qui concerne les lipides. Ce qui signifie que pour optimiser le système de cultures en nombre de rations alimentaires, en prenant comme référence, le nombre de rations en glucide, il faut améliorer les rendements en protéines et lipides.

Le Tableau 8 rend compte, pour les deux expérimentations, de l'intensité territoriale des deux systèmes de culture.

Les associations de cultures TZEEWArachide (495,6 $\mathrm{m}^{2}$ ) et Maïs-Manioc-Cajanus $\left(1521,9 \mathrm{~m}^{2}\right)$ ont exigé moins de superficies.

L'estimation des rendements en nombre de rations alimentaires équilibrées en macronutriments montre que les cultures associées améliorées par une fertilisation adéquate, peuvent réduire l'intensité territoriale des exploitations agricoles et contribuer ainsi à la préservation des forêts et des savanes.

Mais avec l'approche de l'évaluation de la productivité (Tableau 7) par la capacité des systèmes de cultures à approvisionner les populations en rations alimentaires équilibrées en macronutriments, d'importantes quantités 
de la production alimentaire ne sont pas prises en compte comme le montre le Tableau 9.

En effet, en dehors de l'arachide en culture mono spécifique, la production de lipides est le principal facteur qui limite le nombre de rations alimentaires équilibrées en macronutriments.

En conséquence, le pourcentage de protéine et surtout de glucide non pris en compte est très élevé. Ainsi, pour les trois variétés de maïs en culture mono-spécifique, le pourcentage moyen non utilisé est de $367 \%$ pour les glucides et de $189 \%$ pour les protéines. Par contre pour les systèmes de cultures associées, ces pourcentages varient de $3,3 \%$ à $46 \%$ pour les glucides et de $34,2 \%$ à $93,9 \%$ pour les protéines.

L'association du maïs, du manioc et du pois d'angole a produit des quantités très élevées de glucides et de protéines, mais très peu de rations équilibrées en raison de la faible production du système en lipides. De ce fait, les reliquats (excès) en glucides et en protéines sont très élevés.

Mais même si l'expression des rendements par le nombre de rations équilibrées en macronutriments rend bien compte de la capacité du système de culture à réduire les carences alimentaires majeures, ces reliquats seront mieux valorisés dans la conversion de la production en rations protéino-énergétiques.

Le remplacement du critère d'évaluation sur la base d'un minimum de lipide par des apports journaliers en énergie alimentaire et en protéines, bonifie le nombre de rations utiles et réduit ainsi l'intensité territoriale (Tableau 10).

Pour la première expérimentation associant l'arachide à trois variétés de maïs, l'efficacité territoriale est améliorée trois fois en moyenne par rapport aux systèmes de cultures mono spécifiques.

En ce qui concerne l'association maïsmanioc-pois d'angole pour la deuxième expérimentation, les améliorations sont de 3 à 20 fois la performance basée sur un minimum de lipide, par des apports journaliers en énergie alimentaire et en protéines. De plus, grâce aux protéines des feuilles du manioc, l'ensemble des trois plantes engendre l'intensité territoriale la plus basse égale à $266,4 \mathrm{~m}^{2}$ pour satisfaire les besoins protéinoénergétiques pendant un an.

Tableau 3: Rendements en grains des différents systèmes de culture.

\begin{tabular}{lccc}
\hline Systèmes de cultures & \multicolumn{3}{c}{ Rendement (kg/ha) } \\
\cline { 2 - 4 } & \multicolumn{1}{c}{ Grains (maïs) } & Graines (arachide) \\
\hline Arachide (mono spécifique) & - & $1785,4 \pm 116,6 \quad \mathrm{a}$ \\
\hline Maïs (mono spécifique) & $2973 \pm 147,7$ & $\mathrm{c}$ & - \\
TZEEW & $4167 \pm 305,9$ & ab & - \\
OBATANPA & $4770 \pm 347,7$ & a & - \\
DMR-ESRW & $2778 \pm 46,3$ & c & $1157 \pm 43,6 \quad$ b \\
\hline Maïs et Arachide & $3496 \pm 212,3$ & bc & $942 \pm 36,4 \quad$ bc \\
TZEEW -Arachide & $3620 \pm 200$ & bc & $812 \pm 32,6 \quad$ c \\
OBATANPA - Arachide & &
\end{tabular}

DMR-ESRW: Dowly Middew, Resistent Early Streak White; TZEEW: Tropical Zea Extra Early White ; a, b, c : Les valeurs d'une même colonne, suivies de différentes lettres sont statistiquement différentes avec $p<0.0001$ avec $\alpha=0,01$ (Comparaison par paire par le test de Turkey HSD). 
Tableau 4 : Rendements en matière sèche totale des différents systèmes de cultures en kg/ha.

\begin{tabular}{llccc}
\hline Systèmes de cultures & Grains /Graines & Racine & Feuilles \\
\hline Association & Maïs & $2990,4 \mathrm{~b}$ & - & - \\
& Manioc & - & $5175 \mathrm{c}$ & 422,7 \\
& Cajanus & $703,8 \mathrm{c}$ & - & - \\
& Ens. Syst & $3694,5 \mathrm{a}$ & $5175 \mathrm{c}$ & 422,7 \\
\hline Monoculture & Maïs & $3413,2 \mathrm{a}$ & - & - \\
& Manioc & - & $6456,5 \mathrm{~b}$ & 553,9 \\
& Cajanus & $858,6 \mathrm{c}$ & - & -
\end{tabular}

a, b, c : les valeurs d'une même colonne, suivies de différentes lettres sont statistiquement différentes avec $\mathrm{p}<0,0001$ (Comparaison par paire par le test de Turkey HSD).

Tableau 5 : SER des systèmes de cultures associant l'arachide et trois variétés de maïs et de l'association maïs-manioc-pois d'angole.

\begin{tabular}{lc}
\hline Systèmes de cultures & Surface Équivalente Relative \\
\hline Association Arachide - TZEEW & 1,582 \\
Association Arachide - Obatanpa & 1,366 \\
Association Arachide - DMR-ESR & 1,214 \\
Association Maïs-Manioc-Pois d'angole & 2,5 \\
\hline
\end{tabular}

Tableau 6: Quantité (en kg) de macronutriments (glucide, protéine, lipide) dans les deux expérimentations.

\begin{tabular}{lccc}
\hline Systèmes de cultures & Glucide & Protéine & Lipide \\
\hline $\mathbf{1}^{\text {ere }}$ expérimentation & & & \\
Arachide & 371,7 & 432,5 & 794,1 \\
TZEEW & 2090,5 & 248,6 & 130,8 \\
Obatanpa & 2731,2 & 550,6 & 183,4 \\
DMR-ESRW & 3353,6 & 399,2 & 209,9 \\
TZEEW-Arachide & 2194,4 & 512,6 & 636,7 \\
Obatanpa-Arachide & 2658,5 & 688,9 & 572,7 \\
DMR-ESRW-Arachide & 2539,8 & 495,3 & 520,3 \\
\hline 2 $^{\text {ème }}$ expérimentation & & & \\
Maïs mono & 2218,9 & 316,5 & 136,5 \\
Manioc mono & 5934,6 & 247,7 & 97,8 \\
Pois d'angole mono & 489,5 & 140,7 & 12,9 \\
Association MMC & 7094,6 & 808,2 & 207,2 \\
\hline
\end{tabular}


Tableau 7 : Nombre de rations alimentaires résultant des deux types de systèmes de cultures

\begin{tabular}{lcccc}
\hline Systèmes de cultures & $\begin{array}{c}\text { Nombre rations } \\
\text { glucides }\end{array}$ & $\begin{array}{c}\text { Nombre rations } \\
\text { protéines }\end{array}$ & $\begin{array}{c}\text { Nombre rations } \\
\text { lipides }\end{array}$ & $\begin{array}{c}\text { Nombre de rations } \\
\text { équilibrées }\end{array}$ \\
\hline $\mathbf{1}^{\text {ère }}$ expérimentation & 1290 & 7626 & 9188 & 1290 \\
Arachide & 7258 & 4383 & 1514 & 1514 \\
TZEEW & 9483 & 9701 & 2122 & 2122 \\
Obatanpa & 11644 & 7033 & 2429 & 2429 \\
DMR-ESRW & 7619 & 9887 & 7369 & 6628 \\
TZEEW-Arachide & 9230 & 12854 & 6628 & 6022 \\
Obatanpa-Arachide & 8818 & 9402 & 6022 & 1580 \\
DMR-ESRW-Arachide & 7704 & & & 1132 \\
$\mathbf{2}^{\text {ème }}$ expérimentation & 20606 & 7827 & 1580 & 149 \\
Maïs mono & 1699 & 3581 & 1132 & 2400 \\
Manioc mono & 24634 & 13708 & 249 & 200 \\
Pois d'angole mono & & & \\
Association MMC & & & & \\
\hline
\end{tabular}


Tableau 8 : Superficies nécessaires $\left(\mathrm{m}^{2}\right)$ pour satisfaire les besoins alimentaires équilibrés en macronutriments d'une personne.

\begin{tabular}{lcc}
\hline Systèmes de cultures & Superficies nécessaires $\left.\mathbf{( m}^{2}\right)$ & Proportions \\
\hline $\mathbf{1}^{\text {ere }}$ expérimentation & & \\
Arachide & 2831,4 & 1 \\
TZEEW & 2412,5 & 1,17 \\
Obatanpa & 1721,2 & 1,64 \\
DMR-ESRW & 1503,7 & 1,88 \\
TZEEW-Arachide & 495,6 & 5,71 \\
Obatanpa-Arachide & 551,1 & 5,13 \\
DMR-ESRW-Arachide & 606,5 & 4,66 \\
\hline $\mathbf{2}^{\text {eme }}$ expérimentation & & \\
Maïs mono & 2311,7 & 10,60 \\
Manioc mono & 3226,6 & 7,59 \\
Pois d'angole mono & 24513,4 & 1 \\
Association MMC & 1521,9 & 16,11 \\
\hline
\end{tabular}

Tableau 9: Valeurs résiduelles de glucides et de protéines après la satisfaction des besoins alimentaires en rations équilibrées et en macronutriments des deux systèmes de cultures.

\begin{tabular}{lcc}
\hline Systèmes de cultures & \multicolumn{2}{c}{ Reliquat en kg/ha } \\
\cline { 2 - 3 } \multicolumn{1}{c}{ ere expérimentation } & Glucides & Protéines \\
Arachide & 0 & 348 \\
TZEEW & 1712 & 162 \\
Obatanpa & 2183 & 429 \\
DMR-ESRW & 3207 & 261 \\
TZEEW-Arachide & 231 & 142 \\
Obatanpa-Arachide & 717 & 353 \\
DMR-ESRW-Arachide & 1124 & 191 \\
\hline $\mathbf{2}^{\text {ème }}$ expérimentation & & \\
Maïs mono & 1824 & 354 \\
Manioc mono & 5651 & 252 \\
Pois d'angole mono & 452 & 163 \\
Association MMC & 6495 & 641 \\
\hline
\end{tabular}


V. N. ADJAHOSSOU et al. / Int. J. Biol. Chem. Sci. 7(6): 2233-2247, 2013

Tableau 10 : Nombre de rations équilibrées et énergético-protéiques et intensité territoriale des deux systèmes de cultures.

\begin{tabular}{|c|c|c|c|c|}
\hline Systèmes de cultures & $\begin{array}{c}\text { Nombre rations } \\
\text { équilibrées }\end{array}$ & $\begin{array}{c}\text { Intensité } \\
\text { territoriale }\left(\mathbf{m}^{2}\right)\end{array}$ & $\begin{array}{c}\text { Nombre rations } \\
\text { énergético-protéiques }\end{array}$ & $\begin{array}{c}\text { Intensité } \\
\text { territoriale }\left(\mathrm{m}^{2}\right)\end{array}$ \\
\hline \multicolumn{5}{|l|}{$1^{\text {ère }}$ expérimentation } \\
\hline Arachide & 1290 & 2831,4 & 4760,7 & 767,2 \\
\hline TZEEW & 1514 & 2412,5 & 4383 & 833,3 \\
\hline Obatanpa & 2122 & 1721,2 & 6919,5 & 527,8 \\
\hline DMR-ESRW & 2429 & 1503,7 & 7033 & 519,3 \\
\hline TZEEW-Arachide & 7369 & 495,6 & 7693,6 & 474,7 \\
\hline Obatanpa-Arachide & 6628 & 551,1 & 8635,6 & 422,9 \\
\hline DMR-ESRW-Arachide & 6022 & 606,5 & 7834,2 & 466,2 \\
\hline \multicolumn{5}{|l|}{$2^{\text {ème }}$ expérimentation } \\
\hline Maïs mono & 1580 & 2311,7 & 5324,6 & 685,9 \\
\hline Manioc mono & 1132 & 3226,6 & 5581 & 654,4 \\
\hline Pois d'angole mono & 149 & 24513,4 & 3029 & 1205,8 \\
\hline Association MMC & 2400 & 1521,8 & 13708 & 266,4 \\
\hline
\end{tabular}




\section{DISCUSSION}

Pour concilier durablement la satisfaction des besoins alimentaires d'une population mondiale en plein accroissement et la préservation des ressources naturelles, l'évaluation des rendements agricoles devra intégrer la notion de l'intensité territoriale. Elle se définit pour un système de culture donné, comme la surface de base nécessaire pour produire une tonne d'un produit de référence (Riedacker, 2008). Par analogie, la superficie nécessaire pour assurer à un adulte pendant 365,25 jours, soit une ration alimentaire équilibrée en macronutriments (glucides, protéines et lipides), soit pour la même durée, un apport protéino-énergétique journalier de $2163,5 \mathrm{kcal}$ et $56,7 \mathrm{~g}$ de protéines (Cresta et al., 1994). L'intensité territoriale ainsi définie incite à considérer la terre comme une ressource naturelle précieuse et rare, à utiliser parcimonieusement pour préserver le plus de végétations naturelles possible. Cette notion rejoint celle de l'empreinte écologique en tant qu'indicateur du développement durable et conçue comme une estimation de la superficie nécessaire pour maintenir pour une population cible, un niveau de consommation donné (Ledant, 2005; Nativel, 2009).

Les résultats des deux expérimentations associant l'une, l'arachide et trois variétés de maïs de ports différents et l'autre le maïs, le manioc et le pois d'angole, montrent que la compétition pour l'eau et les sels minéraux ne constitue pas un facteur limitant. La pratique des cultures multiples favorise la réduction de l'intensité territoriale (Adjahossou, 2012). En effet, l'association du maïs et de l'arachide par hectare, permet d'éviter le défrichement de 0,2 à 0,6 ha de végétation naturelle contre 1,5 ha pour l'association maïs-manioc-pois d'angole. De même, d'après Bambara et al. (2008), l'amélioration d'un système de cultures associant céréales et légumineuses engendre une augmentation de rendement en grains de $34 \%$ pour le sorgho et de $26 \%$ pour le niébé et un supplément de rendement en paille de $26 \%$ et $45 \%$ pour la fane. Ces résultats sont confortés par ceux de Bedoussac (2009) qui a montré que les associations produisaient jusqu'à $19 \%$ de graines en plus que les cultures mono spécifiques. Cette augmentation de l'efficacité territoriale pourra contribuer à réduire les superficies de terres cultivées. Ses travaux ont par ailleurs révélé que l'association a permis d'augmenter la teneur en protéines du blé dur en situation sans intrant chimique de l'ordre de $25 \%$.

Cette économie de terre pourrait donc être renforcée par un ciblage plus précis de l'agriculture sur la satisfaction des besoins alimentaires, voire nutritionnels. Car dans la plupart des pays en développement, toute la production agricole a pour vocation d'être commercialisable et c'est la partie non commercialisable qui sert à la satisfaction des besoins alimentaires de petits paysans. En conséquence, la production agricole destinée à l'exportation est celle soutenue financièrement et techniquement par les pouvoirs publics. Pour favoriser la sécurité alimentaire, il faut non seulement soutenir les cultures vivrières mais évaluer les systèmes de cultures y afférents à l'aide des paramètres qui concernent directement l'alimentation humaine. L'amélioration des systèmes de cultures mixtes est l'un des moyens pouvant permettre d'améliorer le rendement relatif (Bedoussac, 2009) et ainsi, d'assurer la sécurité alimentaire en région tropicale (Weber, 1976).

Parmi les systèmes de cultures mono spécifiques de la première expérimentation (Tableau 7), le système de cultures à arachide est celui qui a généré le plus faible nombre de rations alimentaires équilibrées en macronutriments à cause de l'insuffisance de la production de glucides. Le système de la variété la plus productive, DMR-ESRW a produit presque le double de la ration de l'arachide (2 429). En moyenne, les systèmes de cultures mono spécifiques ont produit 1 839 rations équilibrées par hectare, tandis que l'ensemble des cultures associées en produisent 6673 . Les associations ont donc produit 3,6 fois plus de rations alimentaires 
équilibrées en macronutriments. Si l'arachide en culture mono spécifique est la moins performante, son association au maïs, améliore qualitativement la production en augmentant la quantité de lipides et de protéines du système de cultures (Adjahossou et al., 2009).

En ce qui concerne la deuxième expérimentation associant le maïs, le manioc et le pois d'angole, le système de cultures associées a généré 2400 rations équilibrées, soit 2,8 fois moins. En effet, bien que très productif en glucides, et dans certaines mesures, en protéines grâce aux feuilles de manioc, la production de lipides par ce système reste faible.

L'évaluation des systèmes de cultures par le nombre de rations équilibrées en macronutriments résulte de la nécessité d'orientation dans le choix des espèces à cultiver, vers non seulement, la suffisance quantitative à travers les bons rendements mais également, une diversité pouvant garantir l'équilibre alimentaire. Cependant, l'apport de lipides qui constitue le facteur limitant dans ce mode d'évaluation, minorant le nombre de rations, est moins préoccupant $\mathrm{du}$ point de vue nutritionnel que de l'apport protéino-énergétique. $\mathrm{Ce}$ qui justifie également l'évaluation des rendements des systèmes de cultures en nombre de rations protéino-énergétiques. Sur cette base, la production de l'association du maïs, du manioc et du pois d'angole dans laquelle toutes les espèces, y compris le manioc, à travers les feuilles, ont apporté une quantité suffisante de protéines pour améliorer le nombre de rations protéino-énergétiques, à raison de 2 163,5 kcal par jour (Cresta et al., 1994).

Ce qui confirme bien que l'efficacité des cultures multiples dans les limites de la disponibilité de l'eau, des sels minéraux et d'une organisation spatiale favorisant un éclairement minimal des plantes de petites tailles dans l'association, la productivité s'acquiert avec le nombre d'espèces associées (Steiner, 1985).
Comme le montre le Tableau 10, on peut observer en ce qui concerne la première expérimentation associant l'arachide au maïs, que l'intensité territoriale définie comme étant la superficie de terre nécessaire pour satisfaire pendant un an, les besoins protéinoénergétiques d'un adulte, varie de $2831,4 \mathrm{~m}^{2}$ pour le système de culture de l'arachide en culture mono spécifique à 495,6 $\mathrm{m}^{2}$ lorsque l'arachide est associée à la variété de maïs TZEEW, à port érigé. Quant à la deuxième expérimentation, l'intensité territoriale varie de $2500 \mathrm{~m}^{2}$ (pois d'angole) en système de cultures mono spécifiques à $1521,8 \mathrm{~m}^{2}$ pour l'association des trois espèces.

Il apparaît donc que les intensités territoriales correspondant aux rations protéino-énergétiques, sont nettement plus faible surtout en ce qui concerne le système de cultures associant le maïs, manioc et le pois d'angole qui nécessite seulement 266,6 $\mathrm{m}^{2}$ pour satisfaire les besoins alimentaires d'un adulte pendant un an.

\section{Conclusion}

Il n'y a pas de doute que l'agriculture moderne, a priori très productive, ne peut prospérer en dehors des règles du marché, fondements de l'économie mondialisée, dans laquelle la rentabilité du temps de travail est un indicateur majeur de la performance. Cependant, l'agriculture étant au commencement de la création de la richesse, et dont l'accomplissement nécessite de nombreuses tâches qui ne sont pas toujours prévisibles, l'expression du coût monétaire à travers la conversion du temps en valeur monétaire aurait pour conséquence de détourner l'activité de sa vocation première qui est de nourrir les hommes. L'évaluation de la performance de l'agriculture a été faite à partir de la minimisation de l'intensité territoriale basée sur la superficie de terre nécessaire pour produire, pour un individu, pendant un an, soit des rations alimentaires équilibrées en macronutriments, soit des rations protéino-énergétiques suffisantes. Elle vise à recentrer dans les pays en 
développement, l'agriculture sur la satisfaction en quantité et en qualité, des besoins alimentaires tout en intégrant les différents aspects de la préservation de l'environnement. Les essais ont montré que la fertilisation modérée des systèmes de cultures associées traditionnels peut contribuer notablement à atteindre ces objectifs.

\section{REFERENCES}

Adjahossou BS, Adjahossou VN, Adjahossou DF, Edorh P, Sinsin B, Boko M. 2009. Aspects nutritionnels d'un système de cultures associant le maïs et l'arachide au Sud-Bénin. Int. J. Biol. Chem. Sci., 3(5): 1141-1150.

Adjahossou VN. 2012. Intensification des systèmes de cultures traditionnels et préservation de l'environnement en Afrique de l'Ouest : le cas du Bénin. Thèse de Doctorat unique, Option Environnement Santé Développement, Université d' Abomey-Calavi, p.279.

Bambara D, Zoundi JS, Tiendrébéogo JP. 2008. Association céréale/légumineuse et intégration agriculture-élevage en zone soudano-sahélienne. Cahiers Agricultures, 17(3): 297-301.

Bedoussac L. 2009. Analyse du fonctionnement des performances des associations blé dur-pois d'hiver et blé dur-féverole d'hiver pour la conception d'itinéraires techniques adaptés à différents objectifs de production en systèmes bas-intrants. Thèse de Doctorat de l'Université de Toulouse, spécialité : Agrosystèmes, écosystèmes et environnement, 233 p.

Bellassen V, Crassous R, Dietzsch L, Schwartzman S. 2008. Réduction des émissions dues à la déforestation et à la dégradation des forêts : quelle contribution de la part des marchés du carbone ? Etude Climat, 14: 43 pages.

Bonny S. 2010. L'intensification écologique de l'agriculture : voies et défis. Innovation and Sustainable Development in Agriculture and Food (ISDA).
Montpellier du 28 Juin au 30 Juin 2010, $11 \mathrm{p}$.

Cresta M, Adandedjan FCC, Vecchi F, Nouwakpo F. 1994. L'alimentation d'une communauté rurale au Sud du Bénin (Sous-préfecture de Zè): les bilans énergétiques des ménages et de leurs composants adultes. Rivista di Antropologia, 72: 15-80.

Fajemissin JM. 1991. Variétés de Maïs Utilisées dans les Essais Régionaux. SAFGRAD 1979-1989. SAFGRADIITA : Bénin ; 71 pages.

Griffon M. 2002. Révolution Verte, révolution doublement verte. Quelles technologies, institutions et recherche pour les agricultures de l'avenir ? Mondes en Développement, 1(117): 39-44.

Griffon M. 1999. Développement durable et agriculture: la révolution doublement verte. Cahiers Agricultures, 8: 259-267.

IRRI. 1974. Annual Report for 1973. Los Banos, IRRI, Philippines.

IRRI. 1975. Cropping Systems. IRRI: Los Banos, Philippines.

Le Roux X, Barbault R, Baudry J, Burel F, Doussan I, Garnier E, Herzog F, Lavorel S, Lifran R, Roger-Estrade J, Sarthou JP, Trommetter M. 2008. Agriculture et Biodiversité. Valoriser les Synergies. Expertise Scientifique Collective, Synthèse du Rapport. INRA: France; $113 \mathrm{p}$.

Ledant J-P. 2005. L'Empreinte Ecologique : un Indicateur de... quoi ? Institut pour un Développement Durable : Asbl ; 1-19.

Mazoyer M, Roudart L. 2002. Histoire des Agricultures du Monde : du Néolithique à la Crise Contemporaine. Edition du Seuil : Paris, France ; p 670.

Nativel C. 2009. Empreinte Ecologique et Alimentation Durable. Observatoire du Management Alternatif. Majeure Alternative Management-HEC : Paris.

Nourrir l'Avenir. 2002. Fiche Ghana Bulletin $\mathrm{n}^{\circ} 17$ de l'Association Sasakawa pour l'Afrique. 
Papy F, Goldringer I. 2011. Cultiver la biodiversité. Courrier de l'Environnement de l'INRA, 60: 55-62.

Purseglove JW. 1979a. Tropical Crops Monocotyledons. Ed. Longman: London; 607.

Purseglove JW. 1979b. Tropical Crops Dicotyledons. Ed. Longman Group Limited: London; 719.

Revel A, Riboud C. 1981. Les Etats-Unis et la Stratégie Alimentaire Mondiale. Calmann-Lévy : Paris ; p.297.

Riedacker A. 2008. Un peu plus d'énergie fossile pour la sécurité alimentaire, le climat et la biodiversité. Les choix mondiaux entre confiance technologique et préoccupations environnementales. Liaison Energie-Francophonie. Québec 80: $56-61$.
Sagbohan A. 1996. Les problèmes alimentaires et nutritionnels dans la ville de Cotonou. In. La Situation Alimentaire et Nutritionnelle dans les Zones Urbaines en Afrique, Nago MC, Hounhouigan JD, de Koning F, Gross R. (Eds). Porto Novo, Bénin ; p 469.

Sahlins M. 1976. Age de Pierre, Age d'Abondance. Jolas $\mathrm{T}$ (trad.). «Bibliothèque des sciences humaines ». Gallimard, coll. : Paris ; 409.

Steiner KG. 1985. Cultures Associées dans les Petites Exploitations Agricoles Tropicales en Particulier en Afrique de l'Ouest. Eschborn, GTZ : Bénin ; 347.

Weber EJ. 1976. La polyculture répond bien aux besoins de petites fermes. Le CRDI Explore, 5 (2). 